\title{
Novela ou romance? A construção da narrativa contemporânea Opisanie Swiata na era da multiplicidade
}

\author{
Novel or novelette? The construction of contemporary narrative in \\ Opisanie Swiata in the era of multiplicity
}

Cloves da Silva Junior ${ }^{1}$

Mestre em Estudos Literários (2016) pelo Programa de Pós-Graduação em Letras e Linguística da Faculdade de Letras da Universidade Federal de
Goiás (FL/UFG). Professor de Língua Portuguesa Golás (FL/NFG). Professor de Lingua Portuguesa da Secretaria de Estado de Educação, Cultura e atualmente, pesquisas sobre a narrativa brasileira contemporânea.

E-mail: cloves-ir@hotmail.com
RESUMO: Este artigo apresenta uma análise da obra Opisanie Świata (2013), de Veronica Stigger, com enfoque para a construção dessa narrativa. As discussões são direcionadas, primeiramente, em torno das teorias sobre novela e romance, no intuito de perceber as características da narrativa que apontam igualmente para esses dois gêneros. Em seguida, a ideia de contemporâneo, desenvolvida por Agamben (2009), será vinculada à obra, ao mesmo tempo em que se discute a presença da narrativa na era da multiplicidade, baseada nas concepções teóricas de Resende (2008). Trata-se de uma pesquisa bibliográfica com base nos postulados de Bakhtin (2010), Carneiro (2005), Eikhenbaum (1971), Soares (2007), dentre outros. Por meio da análise, o texto apresenta a obra de Stigger como uma narrativa híbrida, resultante da fusão entre romance e novela, bem como indica os pontos que caracterizam a obra como pertencente à era da multiplicidade, juntamente com os aspectos da ideia de contemporâneo.

Palavras-chave: Narrativa contemporânea; Hibridismo; Veronica Stigger; Opisanie Świata.

ABSTRACT: This article presents an analysis of Veronica's Stigger work, Opisanie Świata (2013), focusing on the construction of this narrative. The discussions are directed, first, around the theories of novel and romance, in order to perceive the characteristics of the narrative that link to these two genres. Then the idea of contemporary, developed by Agamben (2009), will be linked to work at the same time discussing the presence of the narrative in the era of multiplicity, based on the theoretical concepts of Resende (2008). This is a bibliographic research based on the postulates of Bakhtin (2010), Carneiro (2005), Eikhenbaum (1971), Soares (2007), among others. Through the analysis, the text presents the work of Stigger as a hybrid narrative resulting from the merger between romance and novel, and indicates the points that characterize the work as belonging to the era of multiplicity, along with aspects of contemporary idea.

KEYwORDS: Contemporary Narrative; Hybridity; Veronica Stigger; Opisanie Świata. 


\section{Introdução}

$\mathrm{A}$

literatura brasileira produzida após 1960 é rica em variedade de estilos, técnicas e temas. Essa variedade começou a ser cultivada a partir da abolição de um padrão que agrupava os escritores e escritoras em determinados movimentos literários, e que foi iniciado e consolidado no Modernismo, a partir da Semana de Arte Moderna.

Depois disso, cada escritor e escritora passou a desenvolver o seu estilo de acordo com suas formações literárias e projetos estéticos mais ou menos definidos. Mesmo não existindo padrões que os alinhassem a um determinado movimento, percebe-se, principalmente após 1960, que houve alguns esforços teóricos para nomear o esse contexto diante da multiplicidade dessa produção.

Há críticos que apontam para a existência de um pós-modernismo, definição não muito aceita pela crítica literária. Outros nomeiam como literatura contemporânea, que, numa perspectiva cronológica, de acordo com as pesquisas do Grupo de Estudos de Literatura Brasileira Contemporânea da Universidade de Brasília (UnB), foi iniciada a partir de 1960 a 1965.

Flávio Carneiro (2005, p. 13, grifo do autor) menciona que “[...] em meados dos anos 80, Haroldo de Campos tentava definir o sentimento geral de uma época marcada pela descrença no projeto estético e ideológico proposto pelo modernismo. De acordo com ele, estaríamos vivendo um tempo pós-utópico". Para esse teórico, o termo criado pelo poeta concretista mostra-se mais preciso, por exemplo, do que o termo pós-modernismo, que sugeriria uma ruptura dos projetos estéticos do modernismo.

Como ideia de ruptura, o termo pós-modernismo não seria adequado para caracterizar a produção literária, tendo em vista que várias características presentes no modernismo ainda podem ser encontradas nas obras produzidas após 1960, como a fragmentação das narrativas, que já estava presente em Memórias sentimentais de João Miramar, de Oswald de Andrade.
Carneiro (2005, p. 14) explica também que "tanto a geração de 20 quanto a de 30 eram guiadas por um projeto definido, ousado", que representavam, em certa medida, o desejo de renovação da produção literária, um desejo encarado como missão, a busca pelo ideal. Principalmente a partir de 1980, conforme é afirmado por Haroldo de Campos, não havia um projeto estético e ideológico marcado, e, por isso, a ideia de um tempo pós-utópico.

Beatriz Resende (2008), em seus estudos, lança mão de uma expressão que também pode ser aplicada à produção literária após 1990: a multiplicidade. Essa teórica inicia o primeiro capítulo de sua obra chamando a atenção para o fato de que, ao lidar com a prosa de ficção contemporânea, principalmente as publicações da metade dos anos 1990 até a primeira década do século XXI, é preciso "deslocar a atenção de modelos, conceitos e espaços que nos eram familiares até pouco tempo atrás" (p. 15), tendo em vista que, no cenário literário desse período, especialmente apontado pela teórica, há uma tendência de experimentações e renovações que extrapolam os modelos e conceitos cultivados até o século XX.

Na sequência de suas reflexões, Resende (2008) formula três constatações iniciais que representam as principais dominantes de seu trabalho em relação à produção literária recente: a primeira delas é a fertilidade dessa produção, vislumbrando o surgimento contínuo de novos/as escritores/as e editoras; a segunda é a qualidade dos textos, que possuem experimentações inovadoras e um repertório de referências da tradição literária, dentre outros fatores; e a última constatação é a característica da multiplicidade que

[...] se revela na linguagem, nos formatos, na relação que se busca com o leitor e - eis aí algo realmente novo - no suporte, que, na era da comunicação informatizada, não se limita mais ao papel ou à declamação. São múltiplos tons e temas e, sobretudo, múltiplas convicções sobre o que é literatura [...]".(RESENDE, 2008, p. 18) 
Diante dessas constatações e das discussões constantes em sua obra, Resende (2008) menciona que a prosa contemporânea está situada na era da multiplicidade, uma característica que se mostra como uma reação em relação à tendência homogeneizante proveniente da globalização.

Vale ressaltar, nesse contexto, que os termos pós-utópico e era da multiplicidade não são excludentes, já que o primeiro aponta para uma perspectiva mais ideológica, a princípio, para depois refletir sobre os projetos estéticos da produção recente, e o segundo aponta para a variedade dessa produção a partir das constatações realizadas por Resende (2008). De forma geral, a ideia de multiplicidade apontada por Resende (2008) encontra ressonância com o que foi postulado por Carneiro (2005, p. 34), como pode ser visto na citação a seguir:

Estudar a produção ficcional no Brasil que entra pelo século XXI implica saber que a ficção produzida atualmente pelos escritores mais experientes se alimenta da mesma fonte em que bebem os iniciantes: a linguagem da televisão, da publicidade, do cinema, da Internet, ou da própria tradição literária, não só brasileira. Além disso, os novos partem para a revisão crítica dos que os precederam, propondo uma reescritura cada vez mais presente em nossa produção atual. Cria-se, desse modo, uma via de mão dupla, que não deve passar despercebida.

Quando esse teórico refere-se à fonte que alimenta os escritores novos e os mais experientes, fica evidente a multiplicidade de linguagens que são acessadas para a elaboração do texto literário, revisando e reescrevendo a tradição literária e a história. Essa multiplicidade é motivada pelo surgimento frequente de novas linguagens e tecnologias que permitem a renovação da escrita literária.

Neste trabalho será priorizado, para os fins da análise, o termo cunhado por Resende (2008), com o intuito de verificar como a obra Opisanie Świata, da escritora gaúcha Veronica Stigger, está situada na era da multiplicidade e quais são os recursos utilizados na construção da narrativa que colaboram para essa pluralidade, principalmente levando em consideração o hibridismo de gêneros (novela e romance) e a referência à tradição literária modernista.

A narrativa que serve como corpus de análise deste trabalho retrata a viagem do polonês Opalka até a Amazônia para conhecer seu filho Natanael, que estava doente. No início do percurso, ainda na estação de trem de Varsóvia, Opalka conhece o excêntrico viajante Bopp. O polonês, um tanto introspectivo, mostra-se intrigado com o comportamento singular desse viajante, mas, com o passar do tempo, conta a ele o motivo de sua viagem e o fato de não saber, até aquele momento, da existência do filho Natanael.

Bopp, a partir daí, decide viajar para a Amazônia com Opalka. Deixam o trem e embarcam no navio que os levará a Manaus. Durante o trajeto, várias outras histórias são inseridas na narrativa, enunciadas pelos viajantes que também se encontravam em situação de viagem. Quando chega à Amazônia, Opalka dirige-se ao hospital em que o filho está internado e descobre que Natanael havia falecido.

\section{Opisanie Świata: um gênero híbrido?}

Inicialmente, é preciso destacar a correspondência e a funcionalidade dos elementos paratextuais que acompanham a narrativa. 0 título da obra, Opisanie Świata, que em português significa "descrição do mundo", na capa do livro, foi colocado sobre a carta geográfica do Brasil. Isso, aparentemente, pode ser visto como uma contradição, tendo em vista que há um título em outra língua colocado sobre a carta geográfica de um país que não tem essa língua como oficial. No entanto, é possível entender que a partir do momento em que essa aparente contradição é constatada, há o estabelecimento de um vínculo entre Polônia e Brasil, um vínculo que se traduzirá na viagem 
empreendida pelo protagonista Opalka: trata-se, pois, da linha narrativa que junta os dois países para uma situação de viagem.

A própria escritora Veronica Stigger afirma, em entrevista ao programa Imagem da Palavra ${ }^{1}$, que o fato de colocar o título em polonês representa o desejo de que o leitor também se tornasse um estrangeiro e deslocado, assim como as personagens da narrativa. O leitor, no primeiro contato com a obra, não sabe pronunciar o título e muito menos consegue identificar facilmente a língua de origem da expressão que dá nome à narrativa.

A imersão no espaço polonês começa a acontecer a partir da inserção das imagens iniciais da obra, além da imagem do navio que indica a viagem. São esses elementos que constroem, paulatinamente, a antecipação da narrativa. Ambos indicam o lugar inicial da história e apontam para o modo como o deslocamento será realizado.

Em seguida, há a presença das cartas do médico Dr. Amado Silva, informando a Opalka que seu filho desconhecido, Natanael Martins, estava doente e internado. Aproveita a oportunidade para enviar também a carta do filho que pede que o pai a visite em seu leito de morte. São essas duas cartas que motivam a narrativa que se desenrolará. Funcionam como uma relação de causa e consequência. A narrativa, a viagem, o deslocamento são uma consequência da existência dessas cartas. São elas que representam, ao mesmo tempo, uma situação inicial que não é representada e uma desestabilização dessa situação.

A epígrafe da obra é constituída por duas citações: a primeira extraída do romance Quincas Borba, de Machado de Assis, e que aponta para uma possível viagem à Varsóvia; e a segunda, retirada de uma carta em que Michel Foucault faz referência à peça teatral Ubu rei, escrita por Alfred Jarry, cuja ação

\footnotetext{
A fonte das entrevistas dadas pela escritora estão listadas nas referências bibliográficas ao final do artigo. Ao longo do texto, quando as entrevistas forem apontadas, será feita menção apenas ao programa.
}

se passa na Polônia. Desse modo, percebe-se que os paratextos contribuem para uma espécie de ambientação para a criação de uma atmosfera para capturar o leitor e envolvê-lo na viagem de Opalka.

No tocante à problematização em relação ao gênero da narrativa (novela ou romance), a indagação surgiu, a princípio, em função das considerações de Flora Sussekind - constantes na orelha do livro - quando menciona a existência de um núcleo ficcional mínimo na narrativa de Stigger que caracterizaria essa narrativa como pertencente ao domínio da novela. De outro lado, Veronica, em entrevista ao programa Sempre um papo: a nova literatura brasileira ${ }^{2}$, caracteriza a narrativa como romance. Segundo ela, a novela tem uma estrutura parecida com o conto, algo mais conciso, concentrado, ao passo que o romance daria abertura para o trabalho com mais personagens e ações.

Nesse contexto, faz-se necessário ressaltar que a novela não é um gênero muito cultivado no Brasil; os escritores e escritoras privilegiam o poema, a crônica, o conto e o romance. Quanto à extensão da novela - princípio utilizado por muito tempo para classificar os gêneros -, nos textos teóricos, é comum encontrar referências que balizam a novela entre o conto e o romance.

Para Angélica Soares (2007, p. 54), na novela “[...] constrói-se um enredo unilinear, faz-se predominar a ação sobre as análises e as descrições e são selecionados os momentos de crise, aqueles que impulsionam rapidamente a diegese para o final". Ora, nessa perspectiva, percebe-se que em Opisanie Świata há um enredo unilinear que compreende a viagem de Opalka até a Amazônia. É o percurso da viagem que ganha destaque na narrativa de Stigger, construído sob a égide do cômico, figurativizado, em maior escala, no personagem Bopp.

2 O projeto A nova literatura brasileira, que integra o programa, é um ciclo de 15 encontros que fo relizado A nová Iiteratura brasileira, que integra o programa, é um ciclo de 15 encontros que foi quinze escritores/escritoras que foram ganhadores(as) da Bolsa de Criação Literária da Petrobras. 
Em suas contribuições para a teoria da literatura, Aguiar e Silva (1990, p. 244), quando se refere à narrativa medieval, menciona que a novela é uma

[...] narrativa curta, sem estrutura complicada, avessa a longas descrições, que «se esforçava por contar um facto ou um incidente impressionantes, de tal modo que se tivesse a sensação de um acontecimento real e que esse incidente nos parecesse mais importante do que as personagens que o vivem.

Na narrativa stiggeriana, o fato é a viagem, que ganha maior destaque e extensão do que, por exemplo, a chegada de Opalka a Manaus, o reencontro com o filho desconhecido e morto, a visita à antiga casa em que morava e um princípio de descrição do próprio filho a partir de suas anotações encontradas à mesa. Em termos de extensão, o desfecho do romance não tem tanto espaço quanto à viagem, marcada pela inserção de outras histórias e personagens.

Ainda de acordo com Soares (2007, p. 54-55), "têm aparecido como mais apropriadas à novela as situações humanas excepcionais que [...] se desenvolvem como um corte na vida das personagens, corte este explorado pelo narrador em intensidade, [...]". A partir disso, pode-se afirmar que Opisanie Świata possui uma construção narrativa que engloba esse princípio do gênero novela, visto que o corte na vida das personagens de que trata Soares (2007), na obra de Stigger é a viagem empreendida por Opalka. Não se tem muitas informações sobre o que esso personagem vivenciou até o momento em que está sentado na estação de trem. 0 leitor conhece apenas o que se passa a partir daí e no final da narrativa chega a encontrar certos indícios não muito claros sobre o passado de Opalka. Não se sabe qual a doença que motivou seu regresso à Europa, e sua forma de expressar emoções não são declaradas. É por meio dos gestos que o estado sentimental de Opalka pode ser percebido pelo leitor. Pode-se observar a inquietação na tentativa de ler jornal enquanto lida com o extrovertido Bopp, e também a recusa em enfrentar a morte do filho quando adia a abertura da porta para notar a presença de uma mancha em sua roupa.

Soares (2007, p. 55) explica também que "o predomínio da ação que, muitas vezes, favorece a construção dialogada, dá à novela uma feição dramática [...]. Não mais estruturada através da moldura ou enquadramento dos episódios, como na novela toscana típica [...], ela hoje pouco se diferencia do romance [...]”. A partir dessas considerações, é possível refletir sobre dois aspectos. O primeiro diz respeito à construção dialogada. Apesar de não haver muitos discursos diretos, a narrativa de Stigger apresenta diálogos descritos em discurso indireto que mesclam histórias de Bopp e das outras personagens que também estão em situação de viagem, no trem ou navio.

O segundo aspecto refere-se à estrutura da narrativa. Opisanie Świata não pode ser considerado uma novela toscana típica, no entanto, percebe-se a existência de uma narrativa em moldura, consolidada pelo núcleo ficcional mínimo, apontado por Flora Sussekind, e permeada por outras narrativas que são enunciadas pelas demais personagens, como a história do tio fazendeiro contada por Hans, e acontecimentos que não estão ligados diretamente a esse núcleo ficcional, como a transformação de Priscila Antonini em aranha, conferindo à narrativa uma estrutura episódica, de molduras, construída por uma narrativa maior que possui outras menores encaixadas a ela.

Quando Soares (2007) afirma, nessa última citação, que, na contemporaneidade, a novela pouco se diferencia do romance, já é possível perceber o princípio bakhtiniano sobre o caráter inacabado desse último gênero, que abarca outras formas e gêneros considerados literários ou não. Complementando essa ideia, Eikhenbaum (1971, p. 161-162) assevera que: 
O romance é uma forma sincrética (pouco importa se ele é desenvolvido diretamente a partir da compilação de novelas, ou se é tornado complexo pela inclusão de descrições de costumes); a novela é uma forma fundamental, elementar (o que não quer dizer primitiva). 0 romance provém da história, do relato de viagens; a novela provém do conto, da anedota.

Eikhenbaum (1971) caracteriza a novela como uma forma elementar e destaca a origem do romance a partir do relato de viagens. Assim como Soares (2007), associa-se aos pressupostos de Bakhtin (2010) sobre o romance, visto como o resultado de uma fusão de outros gêneros, possibilidade que se efetiva em função do seu caráter plástico, o que não ocorre propriamente com a novela.

Mesmo quando Bakhtin (2010) discorre acerca do fenômeno de "romancização", mencionando que os demais gêneros tornaram-se mais livres após a supremacia do romance a partir de meados do século XVIII, não é possível precisar, na literatura brasileira, se o gênero novela adaptou-se e desenvolveu-se de forma diferente do costume. Talvez pela ausência de uma produção expressiva de novelas no Brasil, não seja possível determinar se esse gênero adquiriu uma nova roupagem que extrapolasse os moldes engessados em torno de sua definição.

A partir dessas considerações iniciais, percebe-se que a narrativa de Veronica Stigger possui várias ligações com as características do gênero novela, sobretudo pelo corte na vida de Opalka, que gera um enredo unilinear, e pela estrutura episódica. No entanto, ao mesmo tempo, é possível também perceber um vínculo entre o modo de construção dessa narrativa e o gênero romance.

É perceptível que as teorias de Bakhtin (2010) apresentam determinados posicionamentos que podem ser vinculados à obra em discussão para classificá-la também como romance. Se a teoria de Lukács (2009) mostrase um tanto rígida e totalizante para a classificação do romance enquanto gênero, os postulados de Bakhtin (2010) são mais flexíveis em relação a esse assunto. Para o teórico russo:

O romance é uma diversidade social de linguagens organizadas artisticamente, às vezes de línguas e de vozes individuais. [...] É graças a este plurilinguismo social e ao crescimento em seu solo de vozes diferente que o romance orquestra todos os seus temas, todo seu mundo objetal semântico, figurativo e expressivo. 0 discurso do autor, os discursos dos narradores, os gêneros intercalados, os discursos das personagens não passam de unidades básicas de composição com a ajuda das quais o plurilinguismo se introduz no romance (2010, p. 74-75).

Em suas reflexões sobre a teoria do romance, Bakhtin (2010) explica que o plurilinguismo é uma das bases para a construção desse gênero, tendo em vista que o romance necessita de várias vozes para que o discurso romanesco seja consolidado. Em Opisanie Świata há uma estratificação nessa diversidade social de linguagens/vozes, individuais e coletivas, em primeira e terceira pessoa, e no interior dessa última, há uma variedade de outras vozes estratificadas a partir de classe social, gênero, idade, dentre outros fatores, criando uma espécie de confusão de vozes que

[...] se instala como um recurso literário, impossibilitando o conhecimento de quem está falando, se o personagem, se a memória do personagem se sobrepõe à própria escrita, se Veronica Stigger ou o nome colocado na capa do livro, ou todos juntos, criando-se, assim, um diário feito de recortes de um outro texto, só escrito e divulgado anos depois sobre outro escritor de nome Raul Bopp (SILVA, 2015, p. 91).

De forma geral, há uma voz em primeira pessoa, caracterizada a partir de um registro de diário. Percebe-se que se trata das anotações e impressões de Opalka. Além desse registro diarístico, há um outro, na voz de Bopp, constante no capítulo 5, em que esso personagem anota informações sobre os passageiros do navio. No nível do discurso em terceira pessoa, ainda no trem, o leitor entra em contato com a história de Priscila Antonini e 
sua transformação em aranha. Já no navio, a narrativa dá lugar à história das brincadeiras das crianças e da cachorra Margarida, de D. Oliva e suas sobrinhas (as Olivinhas), à festa de Netuno e o batismo dos neófitos, à história contada por Hans sobre o tio que escondia esmeraldas em suas terras, dentre outras.

Ainda sobre a confusão de vozes, faz-se necessário destacar o papel de Bopp para a instalação desse recurso literário. Com seu jeito alegre e comunicativo, esso personagem torna-se responsável por alimentar essa confusão, tendo em vista que é ele quem inicia o diálogo com Opalka e estabelece interações com outras personagens - no trem e no navio - e movimenta os episódios que se sucedem.

Portanto, mesmo com características do gênero novela, a narrativa de Stigger é construída sob as bases do plurilinguismo, que é a premissa básica do romance, de acordo com Bakhtin (2010). O navio, enquanto elemento movente no espaço ficcional da narrativa, é o lugar que abriga essas diversas histórias/vozes que são enunciadas pelas personagens, e que não estão ligadas diretamente ao protagonista Opalka: elas existem independentemente do núcleo principal do enredo, isto é, não foram motivadas pelo desejo do protagonista de conhecer o filho doente.

Bakhtin (2010), na sequência de suas reflexões em torno do plurilinguismo, evidencia que uma das formas mais importantes de introdução e organização desse recurso estilístico no romance é a presença de gêneros intercalados:

0 romance admite introduzir na sua composição diferentes gêneros, tanto literários [...] como extraliterários [...]. Em princípio, qualquer gênero pode ser introduzido na estrutura do romance, e de fato é muito difícil encontrar um gênero que não tenha sido alguma vez incluído num romance por algum autor. Os gêneros introduzidos no romance conservam habitualmente a sua elasticidade estrutural, a sua autonomia e a sua originalidade linguística e estilística (BAKHTIN, 2010, p. 124).
A obra de Stigger, constituída por 17 capítulos de tamanhos irregulares, possui em seu interior um movimento alternado entre os capítulos e os outros gêneros textuais que compõem a narrativa: cartas (4), diários (8), anúncios publicitários (9), trechos de guia de viagens (14), canção (1), comunicado (1) e poema (1). A utilização dessa variedade de gêneros contribui para uma fragmentação da narrativa que, mesmo assim, mantém sua unicidade.

A forma como esses gêneros estão dispostos no livro contribui para a hipótese de que existe um autor ficcional - e não empírico - que organiza a narrativa, como se escolhesse a ordem em que esses gêneros aparecem, iniciando pelas cartas, depois pelos elementos paratextuais e assim por diante. Cria-se a ideia de uma narrativa feita por colagem de vozes, de gêneros textuais, enfim, de linguagens, orquestrada por um autor que está diante do caos e precisa organizar a obra.

Conforme apontou Bakhtin (2010), ainda sobre a presença dos gêneros intercalados no discurso romanesco, a narrativa admite tanto gêneros literários quanto não literários. Em Opisanie Świata tem-se uma mescla dessas duas categorias de gêneros, servindo ao propósito de contextualizar a narrativa na época que representa: os anos de 1930.

Quando se põe em discussão se a narrativa é uma novela ou um romance, é possível convocar a passagem da entrevista dada por Veronica Stigger para o programa Imagem da palavra, em que ela menciona que gosta de experimentar com as formas, testar os limites dos gêneros. Ora, esse teste está bem claro em Opisanie Świata na medida em que se torna perceptível que a escritora conduziu a narrativa a níveis tão elaborados que impedem uma classificação precisa da obra quanto ao gênero.

Entende-se, portanto, que se trata de uma narrativa híbrida que é construída pela fusão entre novela e romance, sem que seja possível classificála como um ou outro gênero, conforme os apontamentos realizados acima com base nos postulados teóricos elencados. 
Nesse sentido, acerca do hibridismo, Vladimir Krysinski (2012) explica que o termo híbrido - proveniente dos campos das ciências naturais, biologia e genética - foi tomado como empréstimo pela teoria e crítica literárias para caracterizar determinadas construções textuais/literárias. Essas construções são entendidas como “[...] operações discursivas de mistura e de cruzamento [...]" (KRYSINSKI, 2012, p. 234).

De modo geral, na literatura, o termo hibridismo pode ser utilizado para a análise de textos que

[...] rompem as fronteiras dos gêneros, transgridem as normas formais estabelecidas e aparecem como produtos de uma combinação, fusão, mistura ou aglutinação de elementos diferentes. Embora esse tipo de texto, segundo alguns teóricos e críticos, exista desde a antiguidade, sua presença progressiva e até mesmo sua proliferação nos séculos XX e XXI fazem com que ele possa ser considerado uma das marcas da literatura contemporânea, [...] (FARIA, 2012, p. 230).

Como afirma Zênia de Faria, há uma presença expressiva de textos híbridos nos séculos XX e XXI, provavelmente em função das frequentes experimentações que são realizadas pelos escritores e escritoras. Neste ponto, pode-se retomar a citação de Carneiro (2005), utilizada na introdução deste artigo para discorrer sobre a produção ficcional do século XXI. Quando esse teórico menciona que os escritores/escritoras incorporam na produção literária a linguagem da televisão, da publicidade, do cinema, da Internet e da tradição literária para promover uma reescritura, é possível entender que há uma reescritura/reutilização dessas linguagens, mas também uma reescritura dos gêneros literários, no sentido de apresentar outras possibilidades não tão engessadas de construção dessas formas literárias, cujos limites vão sendo, paulatinamente, transpostos.

Nesse contexto, é possível pensar, também, resgatando os postulados de Bakhtin (2010), que o hibridismo pode estar intimamente ligado ao fenômeno de romancização bakhtiniano, que permitiu a inserção de outros gêneros no romance e fez com que os demais gêneros se tornassem mais livres, e, portanto, renovados. Nessa perspectiva, é possível conjecturar que, a partir desse fenômeno, diante da frequente penetração de outros gêneros e considerando o dialogismo inerente ao discurso literário, os gêneros literários abriram possibilidades de fusão que podem explicar a presença crescente de textos híbridos na contemporaneidade.

Em suma, a obra em análise valida a tese de Resende (2008) sobre a necessidade de deslocar a atenção dos modelos e definições que eram comuns para encarar uma nova narrativa que não se prende em uma forma cristalizada.

\section{A ideia de contemporâneo e a era da multiplicidade}

Giorgio Agambem (2009), no ensaio "O que é o contemporâneo", ancorado nas reflexões de Nietzsche, explica que o contemporâneo é o intempestivo, é um movimento de dissociação e desconexão. De acordo com os postulados do teórico italiano, ser contemporâneo significaria poder olhar para o passado e para o futuro a partir de certo distanciamento, em uma fratura que permita o direcionamento de um olhar distanciado com capacidade para avaliar "as trevas e a luz": "[...] ser contemporâneo é, antes de tudo, uma questão de coragem: porque significa ser capaz não apenas de manter fixo o olhar no escuro da época, mas também de perceber nesse escuro uma luz que, dirigida para nós, distancia-se infinitamente de nós" (AGAMBEN, 2009, p. 65).

Pensando na ideia de fratura, percebe-se que o trem, e principalmente o navio, permitem que Opalka esteja situado nessa ideia de fenda. A partir de um não-lugar, de um espaço movente que não está ligado à Polônia ou à Amazônia, o protagonista, mesmo de forma introspectiva, consegue ter 
o distanciamento necessário para enxergar "luz e trevas" do ponto em que está. Ao mesmo tempo em que o passado retorna na forma de um filho desconhecido, há uma luz figurativizada na viagem para conhecê-lo.

No navio, a carta e a foto enviadas pelo filho auxiliam na possibilidade de Opalka olhar para um passado que tratou de excluí-lo, e antever um futuro próximo, que talvez não tenha sido realizado de acordo com o esperado, já que o filho não sobrevive à doença inominada.

Assim, quebra e tenção de unir-se é uma imagem da contemporaneidade de acordo com o exposto em [...] Agamben (2009, p. 61). Apostar na escuridão, o desconhecido juntamente com o muito visto mas não observado, eis a atividade sem a qual perde-se a noção do tempo presente. Podemos afirmar que nisto se resume a tarefa à qual se dedica Opalka em Opisanie świata, sem dúvida, uma viagem na tentativa de descrição de um mundo feito de luzes e trevas (MACHADO, 2015, p. 103).

Além disso, essa fratura do contemporâneo também possui outro sentido na construção da narrativa de Stigger. Agamben (2009, p. 71) continua dizendo que, "se, como vimos, é o contemporâneo que fraturou as vértebras de seu tempo (ou, ainda, quem percebeu a falha ou o ponto de quebra), ele faz dessa fratura o lugar de um compromisso e de um encontro entre os tempos e as gerações" (AGAMBEN, 2009, p. 71). A partir da relação estabelecida entre essa citação e o estilo constante na narrativa da escritora gaúcha, é possível perceber o vínculo com o movimento modernista de 1922, não apenas pela referência a Raul Bopp.

Opisanie świata é o ponto de encontro entre a primeira geração modernista e o século XXI. Para Ângela Dias (2015), o parentesco de Veronica Stigger “[...] com o experimentalismo modernista da década de 1920 é óbvio, no que se apropria de uma comicidade leve e piadista, além da composição partida, sintética e descontínua" (DIAS, 2015, p. 62). Portanto, Stigger, ao construir a narrativa, encontra-se na fratura do contemporâneo: direciona seu olhar para o passado a fim de reaproveitá-lo, e a narrativa é o resultado disso.

Nesse contexto, percebe-se uma consonância entre essa afirmação de Agamben (2009) sobre o ponto de quebra como lugar de compromisso e a reflexão de Carneiro (2005) quando diz que os novos escritores propõem uma revisão crítica da tradição. A temática da viagem, da descoberta, frequente na literatura da primeira geração modernista, retorna na narrativa em análise para possibilitar o deslocamento do protagonista e a necessidade de conhecer o filho.

Com o auxílio das referências declaradamente apontadas na seção "Deveres", ao final da narrativa, Veronica revisita e reutiliza elementos que apontam para o contexto modernista, seja a referência a Raul Bopp, ao navio El Durazno, ao poema de Drummond, ou aos fragmentos de ensaios que a escritora incorpora às memórias de Opalka, como pode ser percebido, por exemplo, nas páginas 30-31, em que fragmentos do ensaio "Bopp e o dragão", de Sérgio Buarque de Hollanda, são agregados à narrativa.

Acerca da era da multiplicidade, Resende (2008, p. 20) afirma que “[...] a multiplicidade de nossa literatura aparece como fator muito positivo, original, reativo diante das forças homogeneizadoras da globalização" e prossegue seu discurso ao "[...] reconhecer na multiplicidade um lugar de resistência e liberdade" (RESENDE, 2008, p. 20). Nessa perspectiva, a teórica, quando se refere à era da multiplicidade, utiliza essa expressão indicar a pluralidade da produção literária a partir de 1990.

Para além de uma expressão que caracterize a diversidade de produções literárias e de escritores/as, essa multiplicidade também pode ser investigada no interior das obras, por meio dos discursos enunciados, dos gêneros textuais, dentre outros fatores. Nesse sentido, por estar situada na era da multiplicidade, algumas questões devem ser apontadas na obra Opisanie świata. 
Em primeiro lugar, é necessário destacar a multiplicidade de pontos de vista em primeira e terceira pessoa. Machado (2015), ancorada nos postulados de Norman Friedman (2002), aponta para a existência de um narrador onisciente neutro, que se manifesta em terceira pessoa, e um outro narrador-testemunha, em primeira pessoa. Para Friedman (2002, p. 175, grifos do autor), o narrador onisciente neutro caracteriza-se quando "[...] os estados mentais e os cenários que os evocam são narrados indiretamente, como se já tivessem ocorrido - e sido discutidos, analisados e explicados em vez de apresentados cenicamente como se ocorressem naquele instante".

Sobre essa perspectiva, é possível apontar a seguinte passagem da narrativa de Stigger: "Priscila ajeitou no colo a bolsa e a sacola com o pote de vidro. [...] Priscila abaixou a cabeça e começou a mexer os lábios, mas sem pronunciar palavra. Falava consigo mesma. Talvez rezasse. Bopp tentou restabelecer contato, mas ela o ignorava" (STIGGER, 2013, p. 51). Nesse caso, há um narrador que descreve as ações do personagem Priscila e apresenta informações resultantes de uma possível avaliação, como quando chega à conclusão de que o personagem estava falando consigo mesma e passa a cogitar que talvez estivesse rezando. Ora, tais informações, da forma como estão apresentadas, só podem ter sido elaboradas após uma avaliação dos movimentos do personagem. De outro lado, sobre o narrador-testemunha constata-se que:

O narrador-testemunha é um personagem em seu próprio direito dentro da estória, mais ou menos envolvido na ação, mais ou menos familiarizado com os personagens principais, que fala ao leitor na primeira pessoa. A consequência natural desse espectro narrativo é que a testemunha não tem um acesso senão ordinário aos estados mentais dos outros; logo, sua característica distintiva é que o autor renuncia inteiramente à sua onisciência em relação a todos os outros personagens envolvidos, e escolhe deixar sua testemunha contar ao leitor somente aquilo que ele, como observador, poderia descobrir de maneira legítima (FRIEDMAN, 2002, p. 175-176, grifo do autor).
Um dos exemplos que demonstram a presença desse tipo de narrador é o momento em que Opalka registra suas impressões sobre o excêntrico amigo: “Bopp é livre como uma flecha disparada de um arco. Já rodou o mundo. Tomou sol. Fincou espinho no pé. [...] Bopp não para. Tem bicho-carpinteiro no corpo. Nos dois dias em que tivemos que ficar na estalagem esperando a partida do navio, ele desapareceu" (STIGGER, 2013, p. 60). Desse modo, percebe-se que Opalka faz o uso de seu direito de voz para registrar as impressões que tem sobre o viajante Bopp e só conhece o seu paradeiro depois que o próprio personagem lhe conta onde estava.

Além de Opalka como narrador-testemunha, há também um fragmento de diário em primeira pessoa escrito por Bopp, no capítulo "Meus amigos no navio", em que ele descreve as impressões sobre alguns outros viajantes:

DONA OLIVA. Andaluza. Enviuvou do marido muito cedo. Vive de suas posses. Não tem filhos não tem amantes. [...] Tem pavor de baratas.

AS OLIVINHAS. Andaluzas. Sobrinhas de Dona Oliva. Solteiras e deliciosas. Nunca lembro seus nomes. [...] Acho que estão de flerte comigo.

SENHOR E SENHORA ANDRADE. Brasileiros. Paulistas. Foram reis do café Não são mais. Perderam boa parte de suas fortunas com a crise. [...].

OPALKA. Polonês. Quieto. Discreto. É meu melhor amigo desde o trem. Gosto dele como se deveria gostar de um pai. [...] Eu queria saber rezar para pedir a algum deus, todo dia antes de dormir, que ele ache seu filho com saúde (STIGGER, 2013, p. 72-73).

Nesse fragmento, dois pontos merecem destaque: a função desse registro diarístico para o leitor, o qual passa a conhecer determinadas características das outras personagens que estão no navio, a partir das impressões singulares de Bopp, e a expressão dos sentimentos que nutre em relação a Opalka, e como se compadece da situação do amigo que estava viajando para ver o filho desconhecido.

Após essas considerações sobre os pontos de vista dos narradores, faz-se necessário apontar também para os outros discursos que são 
enunciados pelas personagens e narrados pelo narrador onisciente neutro e que possibilita a existência do plurilinguismo de que fala Bakhtin (2010). Percebem-se as múltiplas vozes que se juntam para a construção da narrativa.

Em segundo lugar, é preciso ressaltar também a pluralidade de personagens/papeis durante a situação de viagem. A narrativa comporta o introspectivo Opalka, o excêntrico Bopp, a misteriosa Priscila Antonini e a estranha transformação em aranha, os singulares marinheiros que conduziram a festa de Netuno, além de outros tipos. Há uma variada gama de personalidades e estilos que juntos somam-se aos demais aspectos da multiplicidade que está presente na narrativa.

Em terceiro, a variedade de gêneros textuais, os quais foram descritos no tópico anterior em que se falou sobre a construção da narrativa, e que colaboram para a pluralidade discursiva do texto. Entre cartas, anúncios e trechos de um guia de viagens - além dos outros gêneros - o texto de Veronica Stigger é construído por meio da fragmentação, atuando como explicação de determinados aspectos ou como ambientação em relação ao contexto da época.

Diante do exposto, e considerando a relação entre a ideia de contemporâneo e a era da multiplicidade, pode-se afirmar - com base na articulação das reflexões de Agamben (2009), Carneiro (2005) e Resende (2008) que essa ideia de contemporâneo alimenta a prosa recente, visto que o escritor/escritora revisa a tradição literária, as novas linguagens de elaboração do texto e as novas tendências, enxerga "as trevas e a luz", e constrói uma nova literatura a partir dessa percepção.

Nessa perspectiva, pode-se dizer que a narrativa brasileira recente é alimentada pelo contemporâneo - assim como o romance foi alimentado pela modernidade -, na busca pela revisão da tradição literária e da história, com o distanciamento necessário para enxergar o escuro e a luz.

\section{Considerações finais}

Acerca da construção desta narrativa de Veronica Stigger, como foi dito no início, entende-se que o fato de ser novela ou romance não reduz o mérito da obra. Diferente disso eleva sua condição na medida em que não se pode determinar com precisão sua forma literária. Assim como a narrativa mostrase inclassificável, há também uma correspondência entre essa narrativa e sua estrutura. Veronica construiu um romance-novela, de modo que seria temerário definir a obra como um ou outro gênero, especificamente. Tanto o romance como a novela estão imbricados, fundidos numa só matéria.

No que se refere à relação entre a ideia de contemporâneo e a era da multiplicidade vê-se que é uma reflexão válida, à medida que a primeira dá os subsídios necessários para a segunda. É o pensamento contemporâneo e a habilidade de enxergar "trevas e luz" que permite ao escritor renovar continuamente a produção literária em busca de novas formas (e não fôrmas) para a escrita das obras.

Opisanie świata representa bem essa ideia de renovação, em função de seu processo de construção da narrativa por meio de múltiplas linguagens, personagens, gêneros textuais e pontos de vista.

\section{Referências}

AGAMBEN, Giorgio. O que é o contemporâneo? In: O que é o contemporâneo e outros ensaios. Tradução Vinícius Nicastro Honesko. Chapecó: Argos, 2009.

AGUIAR E SILVA, Vítor Manuel de. 0 romance: história e sistema de um género literário. In: Teoria e metodologia literárias. Lisboa: Universidade Aberta, 1990.

BAKHTIN, Mikhail. O discurso no romance. In: Questões de literatura e estética: a teoria do romance. Tradução Aurora F. Bernardini et al. 6. ed. São Paulo: Hucitec, 2010.

CARNEIRO, Flávio. No país do presente: ficção brasileira no início do século XXI. Rio de Janeiro: Rocco, 2005. 
DIAS, Ângela Maria. A descrição do mundo de Verônica Stigger ou uma antropofagia desidratada. O Eixo e a roda, Belo Horizonte, v. 24, n. 1, p. 61-76, 2015. http://dx.doi. org/10.17851/2358-9787.24.1.61-76

EIKHENBAUM, Boris. Sobre a teoria da prosa. In: EIKHENBAUM, Boris; TOLEDO, Dionísio de Oliveira. (Org.). Teoria da literatura: formalistas russos. Porto Alegre: Globo, 1971.

FARIA, Zênia de. Apresentação. In: KRYSINSKI, Vladimir. Sobre algumas genealogias e formas do hibridismo nas literaturas do século XX. Tradução e apresentação de Zênia de Faria. Revista Criação \& Crítica, n. 9, p. 230-241, nov. 2012. http://dx.doi.org/10.11606/ issn.1984-1124.v5i9p230-241

FRIEDMAN, Norman. O ponto de vista na ficção: o desenvolvimento de um conceito crítico. Tradução Fábio Fonseca de Melo. Revista USP, São Paulo-SP, n. 53, p. 166-182, mar./mai., 2002. http://dx.doi.org/10.11606/issn.2316-9036.v0i53p166-182

KRYSINSKI, Vladimir. Sobre algumas genealogias e formas do hibridismo nas literaturas do século XX. Tradução e apresentação de Zênia de Faria. Revista criação \& crítica, n. 9, p. 230-241, nov. 2012. http://dx.doi.org/10.11606/issn.1984-1124.v5i9p230-241

LUKÁCS, Georg. A teoria do romance: um ensaio histórico-filosófico sobre as formas da grande épica. Tradução José Marcos Mariani de Macedo. 2. ed. São Paulo: Duas Cidades; Ed. 34, 2009.

MACHADO, Madalena Aparecida. A descrição inacabada do mundo, uma leitura de Opisanie świata, de Veronica Stigger. O Eixo e a roda, Belo Horizonte-MG, v. 24, n. 1, p. 93-106, 2015. http://dx.doi.org/10.17851/2358-9787.24.1.93-106

RESENDE, Beatriz. Contemporâneos: expressões da literatura brasileira no século XXI. Rio de Janeiro: Casa da Palavra, 2008.

SILVA, Gustavo Ramos da. Depois do fim do mundo: a Opisanie Świata de Veronica Stigger. 2015. 187 f. Dissertação (Mestrado em Literatura) - Universidade Federal de Santa Catarina, 2015.

SOARES, Angélica. 0 texto, a teoria. In: Gêneros literários. 7. ed. São Paulo: Ática, 2007. (Série Princípios).

STIGGER, Veronica. Imagem da palavra. Belo Horizonte-MG, Rede Minas, 12/12/2013. Entrevista a Guga Barros. Disponível em: https://www.youtube.com/watch?v=9NHFFg D0DvM (parte I); https://www.youtube.com/watch?v=vHywMF-ztLI (parte II). Acesso em: 06 jan. 2016.

STIGGER, Veronica. Opisanie Świata. São Paulo: Cosac Naify, 2013.
STIGGER, Veronica. Sempre um papo: a nova literatura brasileira. Belo Horizonte-MG, TV Câmara, 11/11/2013. Entrevista a Rômulo Medeiros. Disponível em: <http://www2 camara.leg.br/camaranoticias/tv/materias/SEMPRE-UM-PAPO/467641-A-NOVALITERATURA-BRASILEIRA---PROGRAMA-4.html>. Acesso em: 06 jan. 2016.

Recebido em 19/07/2016

Aceito em 17/12/2016. 